\title{
MECHANOMEDICINE: applications of mechanobiology to medical sciences and next-generation medical technologies
}

\author{
Keiji NARUSE \\ Department of Cardiovascular Physiology, Graduate School of Medicine, Dentistry and \\ Pharmaceutical Sciences, Okayama University, 2-5-1 Shikata-cho, Kita-ku, Okayama 700-8558, \\ Japan
}

Submitted July 4, 2018; accepted in final from August 3, 2018

\begin{abstract}
Mechanical stress underlies most aspects of cell and organismal biology. Mechanomedicine is a field of biology that seeks to understand molecular, cellular, tissue, organ, and individual responses to mechanical stimuli and aims to apply the gained knowledge to improve health. Combining biology and engineering, we explore research areas including mechanosensitive ion channels, heart failure, and regenerative medicine. This review will describe our findings in mechanobiology, our establishment of a joint venture business as we developed devices responding to medical needs, and our alliance with other companies.
\end{abstract}

Key words: mechanobiology, bioventure, stretch-activated ion channel, hemostat

\section{Introduction}

Human bodies are constantly exposed to mechanical stimuli, such as elastic-dynamic stimuli that act on the heart, including stretch and shear stress, as well as fluid-dynamic stimuli that act on blood vessels, including shear stress and hydrostatic pressure resulting from blood flow. In an effort to experimentally reproduce these mechanical stimuli, the author has developed a variety of systems since becoming a graduate student, including stretch chambers made of silicone resin that allow the application of stretch to cells (Fig. 1) as well as a microfluidic dynamic-based microchannel allowing the application of shear stress stimuli (Fig. 2). The author has researched mechanoreceptors and intercellular signal transduction mechanism using these mechanical stress loading systems (1-7), and strong demands for their commercial use were made by the surrounding researchers every time these systems were presented at a conference and published in a paper. These loading systems were originally supplied as self-built devices. Thereafter, a joint venture company "STREX

Corresponding author: Keiji Naruse, Department of Cardiovascular Physiology, Graduate School of Medicine, Dentistry and Pharmaceutical Sciences, Okayama University, 2-5-1 Shikata-cho, Kita-ku, Okayama 700-8558, Japan

Phone: 086-235-7114 Fax: 086-235-7430 e-mail: knaruse@md.okayama-u.ac.jp

C2018 The Japan Society of Smooth Muscle Research 
A

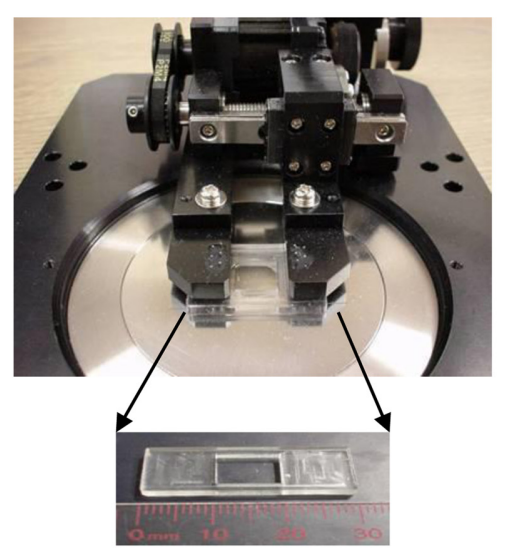

C

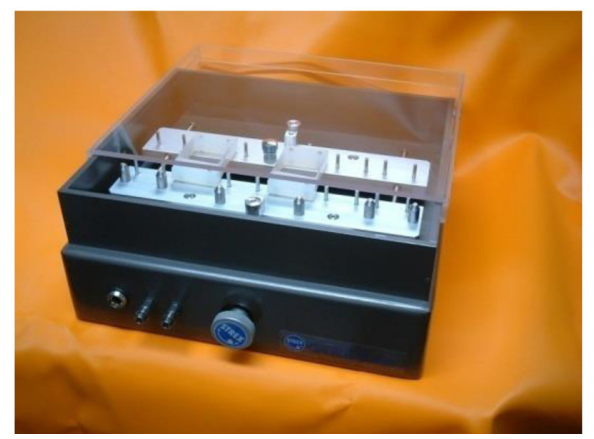

B
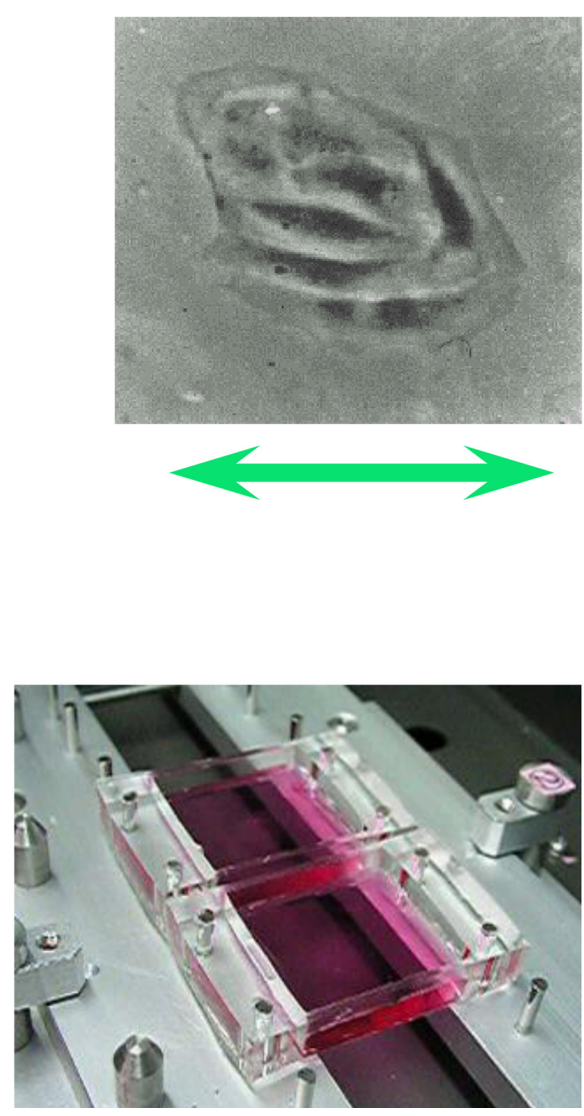

Fig. 1. A: The stretch apparatus for a microscope and the stretch chamber. B: An endothelial cell subjected to stretch. $\mathrm{C}$ : The stretch apparatus for biochemical experimenation.

Inc." engaged in research and development of these systems was established in response to a trend where new ventures were created in collaboration with industry, government and academia. We initially focused on developing systems for loading mechanical stress to cells and tissues for use in regenerative medicine, but later also entered the field of fertility treatment, after the utility of these systems in this field had been confirmed. Here, we introduce our mechanical stress loading systems from its establishment until its exit.

\section{Outline of our joint venture establishment}

As described above, the number of inquiries made from researchers specializing in the fields of cardiology, orthopedics and dermatology about the availability of the mechanical stress loading systems greatly increased with increased frequencies of presentation of our research results. The author had responded to their demands by supplying self-built systems as a graduate student, but became unable to do so with the large increase in inquiry frequency. In 2002, the author therefore launched a university-oriented joint bio-venture company, "STREX Inc." in collaboration with Mrs. Ishida (member of a laboratory instrument manufacturer, Scalatech Inc., Osaka, Japan) and Masumoto (the CEO at B-Bridge International Inc., Silicon Valley, USA), and consequently commercialized these loading systems. Although the author had prepared for a business start-up for several years, transformation of national universities into independent administrative institutions made it dramatically easier to launch a university-oriented joint venture company. STREX Inc. is the first joint bio-venture company originating from Nagoya University. 


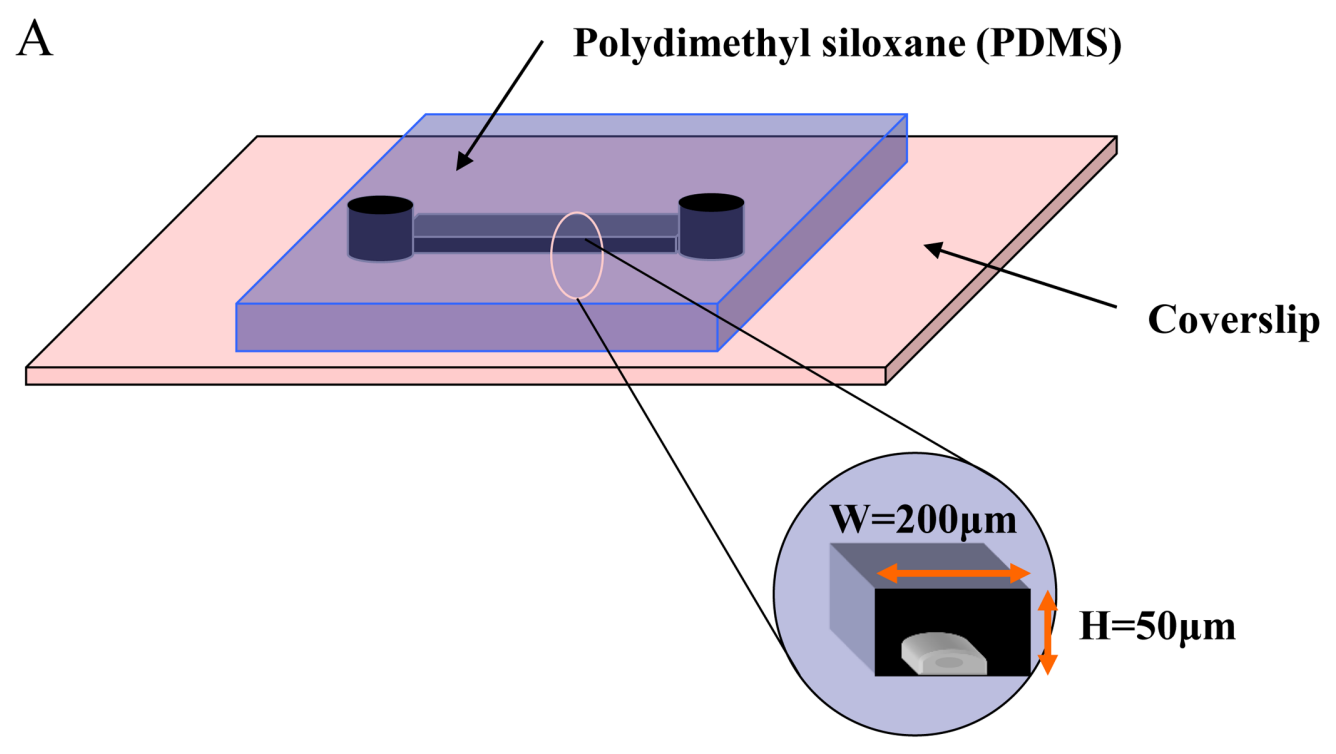

B
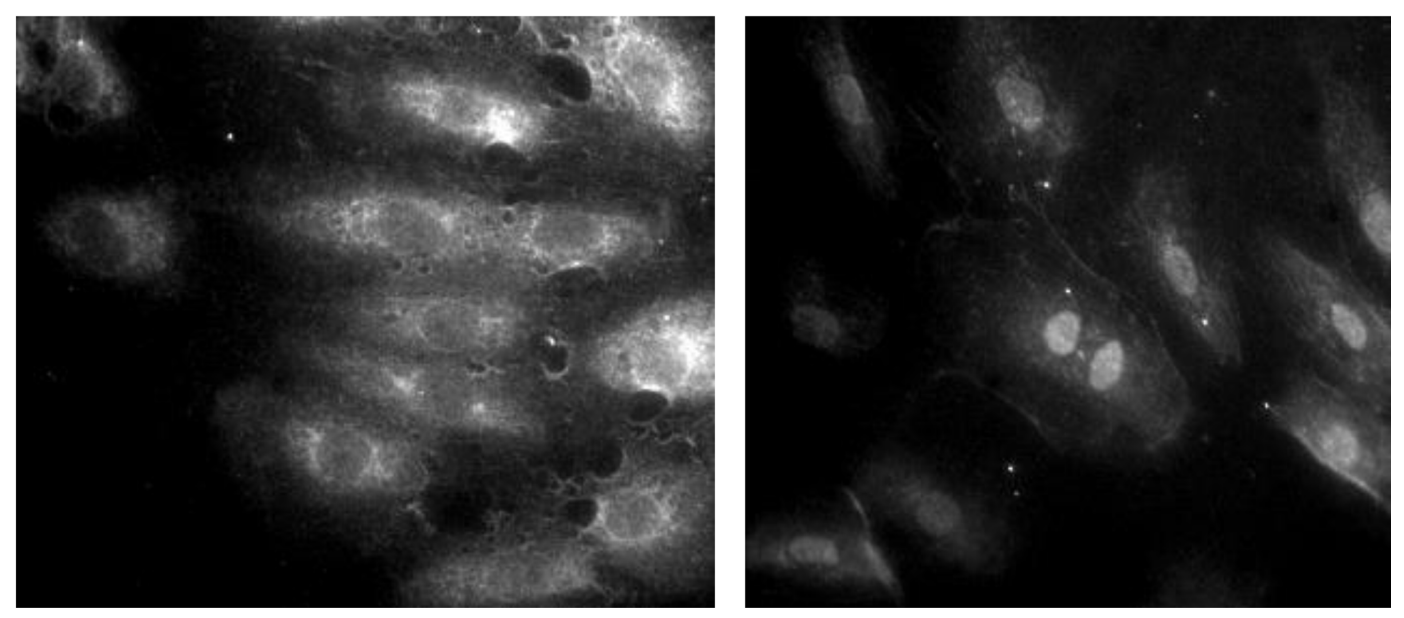

Fig. 2. Microfluidic device to apply shear stress to cells. A:Cell cultures in a microchannel chip. Shear stress can be generated in the microchannel. B:Activation of NFkB in response to shear stress (left; control, right; shear).

\section{Device development responding to medical needs}

\section{Stretch device}

Airway smooth muscle (ASM) cells within airway walls are continuously exposed to mechanical stimuli, such as mechanical stretch and compression, and exhibit various cellular functions such as contraction, proliferation, and cytoskeletal remodeling, all of which are implicated in the pathophysiology of asthma. Using the uni-axial cyclic stretch device, a single stretch for $3 \mathrm{sec}$ elicited a transient increase in $\left[\mathrm{Ca}^{2+}\right]_{\mathrm{i}}$ in human bronchial smooth muscle cells cultured on an elastic silicone membrane. The augmented $\left[\mathrm{Ca}^{2+}\right]_{\mathrm{i}}$ due to stretch was completely abolished by removal of extracellular $\mathrm{Ca}^{2+}$ and was markedly attenuated by an application of $\mathrm{Gd}^{3+}$, an inhibitor of SA channels, or ruthenium red, a transient receptor potential vanilloid (TRPV) inhibitor. In contrast, the stretch-induced rises of $\left[\mathrm{Ca}^{2+}\right]_{\mathrm{i}}$ were not altered by other $\mathrm{Ca}^{2+}$ channel inhibitors such as nifedipine, BTP-2, and SKF-96365 (8). 
A

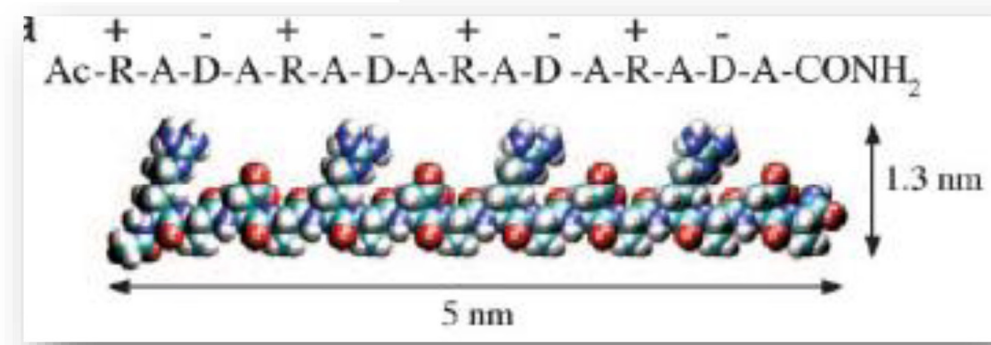

B

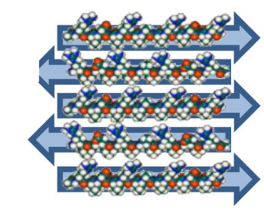

Bilayer structure of the peptide nanofiber

\section{$\boldsymbol{\beta}$-sheet structure}
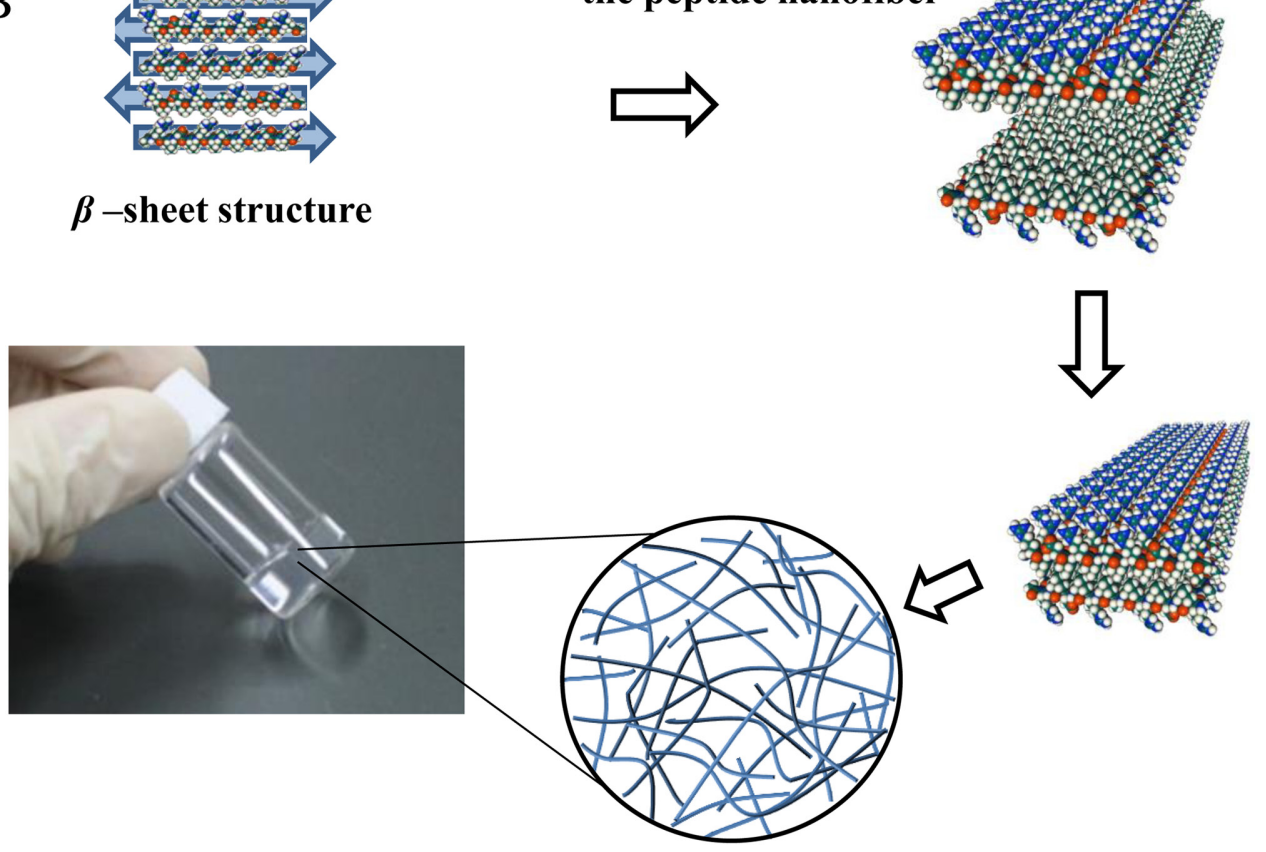

Fig. 3. The self-assembling peptide SPG-178 hydrogel scaffold. A: A molecular model of SPG178. B: A schematic diagram of the formation of the hydrogel from the peptide monomer.

\section{Regenerative medicine}

In an in vivo environment, cardiac muscle, tendon, skeletal muscle, and dermal tissue are constantly mechanically stimulated, and adapt their phenotype (function and form) to changing conditions. Genes and proteins responsive to such mechanical stimuli (stretch, shear and hydrostatic pressure) are suggested to be involved in this process. Tissue transplantation is often necessary in the treatment of heart failure after myocardial infarction, as well as skin burns, tendon rupture, bone tumor and bone fracture. Therefore, we developed systems for applying mainly mechanical stretch stimuli to three-dimensional cultured cells and tissues to initiate a project in which the functions of the three-dimensional structured tissues are constructed and evaluated using the aforementioned systems. Candidate cell sources at this stage would naturally include pluripotent stem cells and somatic stem cells. However, use of these cells is still at the pre-clinical stage. We initiated research at STREX Inc. with support from the New Energy and Industrial Technology Development Organization, but the use of these cells as medical materials had limitations especially in terms of patient safety. Thus, we focused on a contact lens material which was stretchable and approved for use as medical 
A

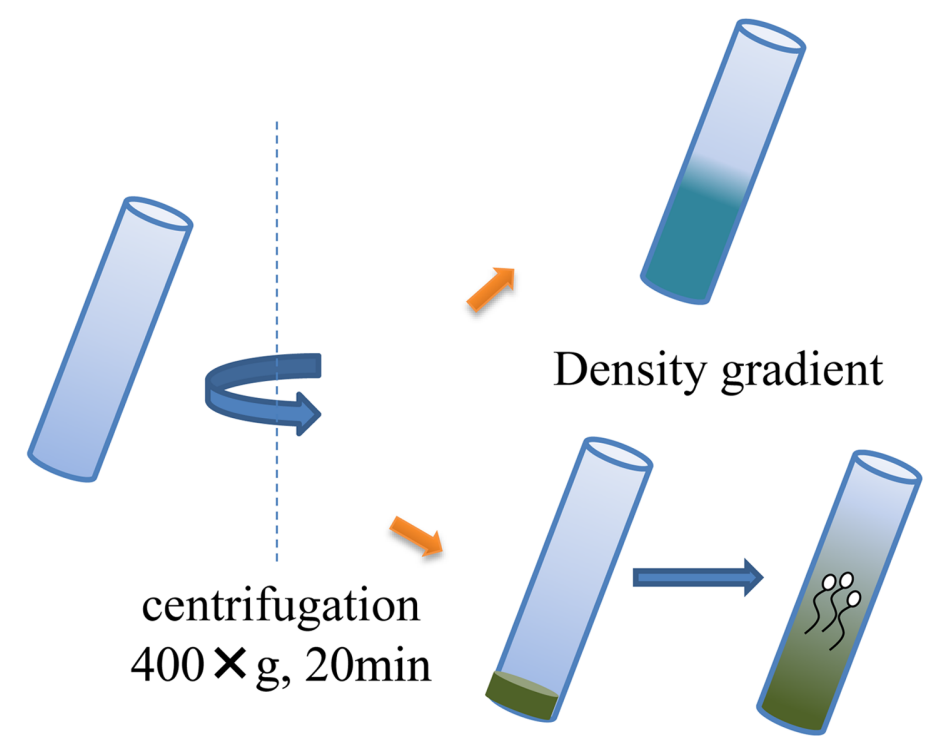

Swim-up

$\mathrm{B}$

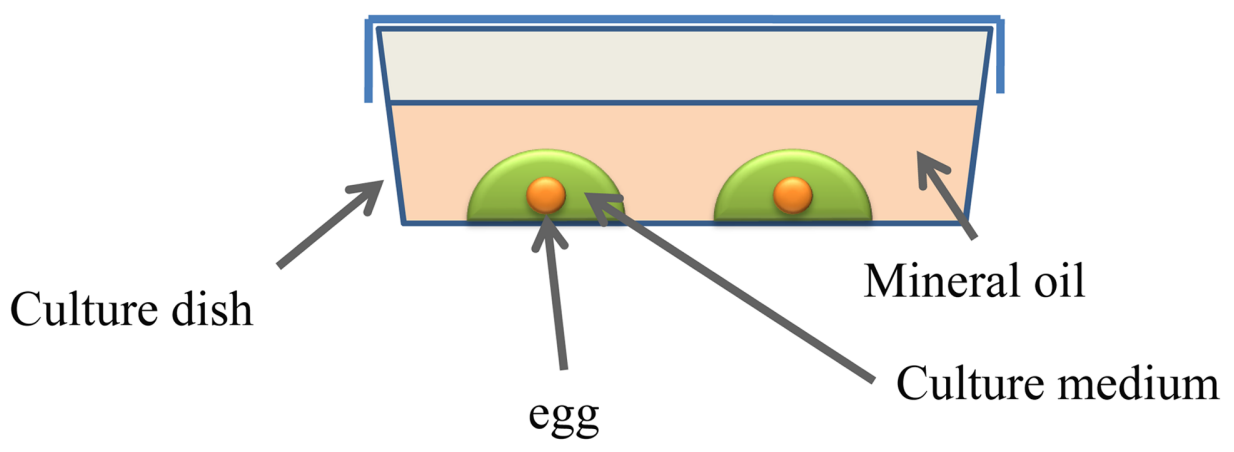

Fig. 4. Current treatment modalities for infertility. A: swim-up and density gradient centrifugation methods for sperm separation. B: static culture with mineral oil for fertilized egg cell culture.

materials in countries including Japan, the United States, and Europe. The next generation soft contact lenses are made of polydimethylsiloxane (PDMS), which has excellent properties. This led to the development of a stretch chamber made of this medical material in collaboration with Menicon Co., Ltd.

In regenerative medicine, three-dimensional cell cultures are required to construct tissues, for which collagen is commonly used as the scaffold. Collagen, derived from animals, contains unknown infectious factors and growth factors, and thus is not suitable for use in human clinical research. This observation led us to develop a self-assembling peptide of appropriate intensity and extension levels through an original molecular design (Fig. 3). A study confirmed that various types of cells including cardiomyocytes can optimally be cultured and exposed to stretch stimuli in this peptide gel (9). Another study found that this self-assembling peptide can be used as a hemostatic agent (10). Currently, pre-clinical and safety studies on this agent are being conducted. Aiming toward approval of this self-assembling peptide for use as a medical material, we are coordinating with the Pharmaceuticals and Medical Devices Agency. 


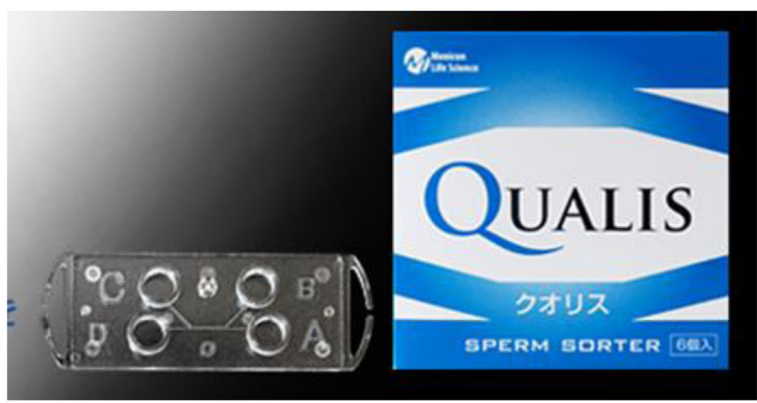

[3]

[2]

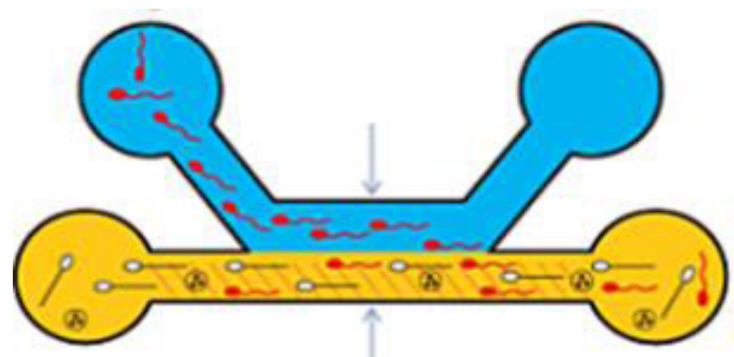

[4]
[1]

Width $=400 \mu \mathrm{m}$, height $=50 \mu \mathrm{m}$

Fig. 5. Microfluidic motile sperm sorter Qualis ${ }^{\circledR}$ is composed of four chambers named as Chamber [1], [2], [3], [4] and a micro channel being connected to each chamber. After applying sperm sorting medium to Chamber [2], [3], [4] and semen sample to Chamber [1] at an appropriate amount, two streams of fluid with laminar flow can be formed in parallel $([1] \rightarrow[4],[2] \rightarrow[3])$. Only motile spermatozoa are able to swim into the parallel stream, after which they are isolated in Chamber [3].
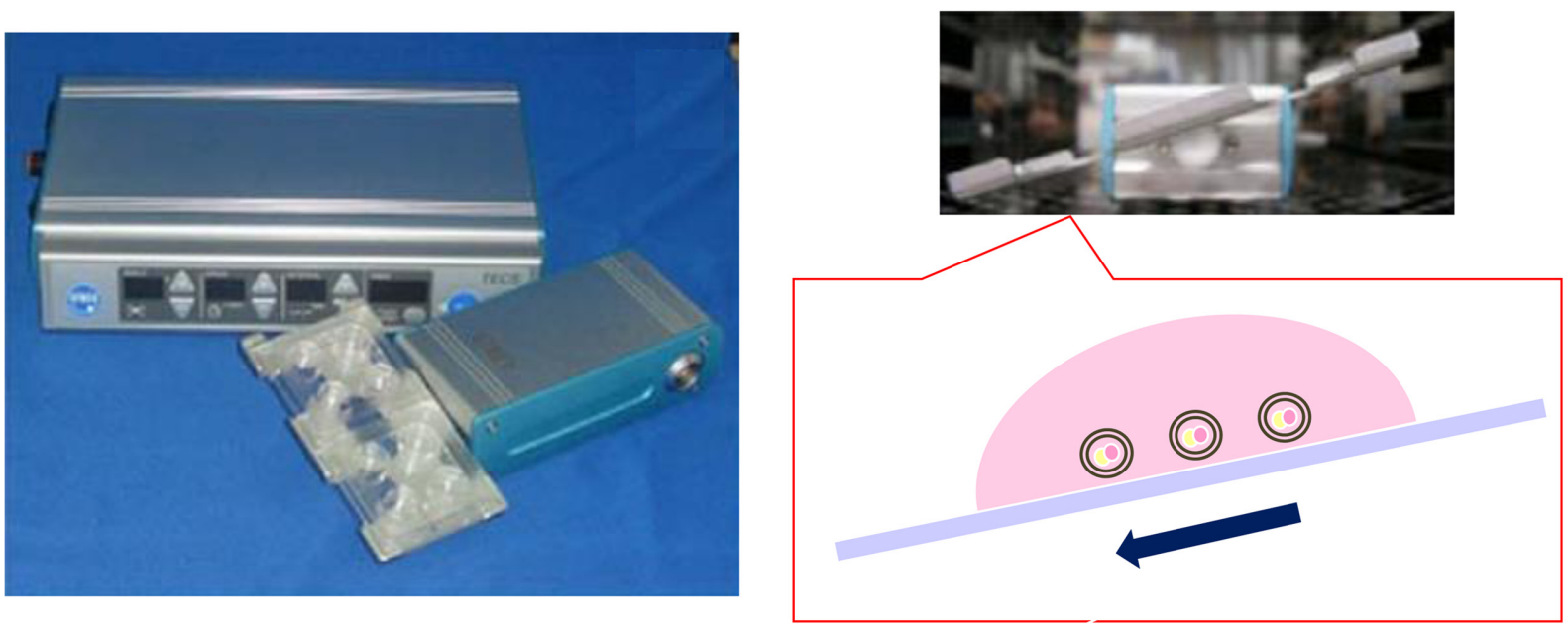

Fig. 6. Tilting Embryo Culture System. This device consists of a control unit and a motor unit with a tilting plate where four-well chambers can be mounted. Mouse embryos were cultured at a tilt angle of 20 degrees with a holding time of $1 \mathrm{~min}$, and then rotated at a tilt angle of -20 degrees with a holding time of $1 \mathrm{~min}$, after which the cycle is repeated.

\section{Infertility}

Declining birth rate is a major social problem in Japan. One in every 10 couples is not able to conceive within 2 years after marriage. Fertility treatment is not covered by health insurance with a cost of a single treatment being half a million to one million yen, and the chance of achieving pregnancy after one treatment is low at approximately $20 \%$. Some young couples experience difficulty in continuing fertility treatment due to problems associated with its high cost. This phenomenon may contribute to the declining birth rate.

Therefore, we developed a microchannel system for separation of motile sperm and a fertilized egg cell culture system capable of applying mechanical stress to cells. Current treatment modalities for infertility include swim-up and density gradient centrifugation methods for sperm separation as well as static culture with mineral oil for fertilized egg cell culture, which are not only performed under conditions greatly differing from the physiological condition, but also have unfavorable effects on sperm and fertilized egg cells (Fig. 4). Our novel system consists of a microfluidic device (Fig. 5) based on devices for cell biological studies (partial 
treatment of cells using laminar flows: PARTCEL) (11) which was developed in collaboration with Takayama, Ph.D., (Professor at University of Michigan) as a student at Harvard university as well as a device based on the mechanical stress loading system (Fig. 6). Our system can reproduce the physiological environment necessary for sperm and a fertilized eggs within the fallopian tube, by eliminating, as far as possible, the unfavorable effects caused by conventional methods. A pre-clinical study conducted in a university and subsequent investigator-initiated studies showed favorable outcomes of the use of our system. Please refer to our papers and review articles for details including the principles of our system $(12,13)$.

\section{Alliance with other companies}

In our joint venture's commercialization of medical-grade devices, many hurdles associated particularly with funds, human resources, materials, manufacturing facility and validation needed to be overcome. Our company was affected by the bankruptcy of Lehman Brothers, and was therefore forced to downsize. Our business was partly transferred to Menicon, because we had already generated intellectual property and our product development had greatly progressed. These phenomena led to the establishment of the Life Science Department within Menicon Co., Ltd. With the know-how of Menicon with its good track record in research, development, manufacturing and sales, performed practical application of our newly developed system, allowing commercial availability of "Sperm Sorter Qualis ${ }^{\circledR}$ " as well as its approval from FDA (Food and Drug Administration) in June of this year. Sperm Sorter Qualis ${ }^{\circledR}$ is currently used in clinics and hospitals specializing in fertility treatment in Japan. In addition, our self-assembling peptide scaffold for three-dimensional culture is commercially available under the brand name of "PanaceaGel" in Japan, Europe and the United States through B-Bridge International.

\section{Conclusion}

Taken together, we experienced many challenges in conducting our pre-clinical and clinical research in academia, but finally succeeded in developing a commercial organization based on our research results. However, we are highly motivated by the fact that use of new principle can help difficult-to-treat patients.

\section{Conflict of interest}

The author is a research adviser of Menicon Co., Ltd., and obtains grants and a consultancy fee from MENICON.

\section{Acknowledgments}

This work was supported by Grants-in-aid for Scientific Research (S) (26220203) and by Grant-in-Aid for Exploratory Research (17K20108) from the Ministry of Education, Science, Sports and Culture of Japan.

\section{References}

1. Naruse K, Yamada T, Sokabe M. Involvement of SA channels in orienting response of cultured endothelial cells to cyclic stretch. Am J Physiol. 1998; 274(5 Pt 2): H1532-8. [Medline] 
2. Naruse K, Yamada T, Sai XR, Hamaguchi M, Sokabe M. Pp125FAK is required for stretch dependent morphological response of endothelial cells. Oncogene. 1998; 17(4): 455-63. [Medline] [CrossRef]

3. Naruse K, Sai X, Yokoyama N, Sokabe M. Uni-axial cyclic stretch induces c-src activation and translocation in human endothelial cells via SA channel activation. FEBS Lett. 1998; 441(1): 111-5. [Medline] [CrossRef]

4. Kanzaki M, Nagasawa M, Kojima I, Sato C, Naruse K, Sokabe M, Iida H. Molecular identification of a eukaryotic, stretch-activated nonselective cation channel. Science. 1999; 285(5429): 882-6. [Medline] [CrossRef]

5. Wang N, Naruse K, Stamenović D, Fredberg JJ, Mijailovich SM, Tolić-Nørrelykke IM, Polte T, Mannix $\mathrm{R}$, Ingber DE. Mechanical behavior in living cells consistent with the tensegrity model. Proc Natl Acad Sci USA. 2001; 98(14): 7765-70. [Medline] [CrossRef]

6. Zhu X, Mills KL, Peters PR, Bahng JH, Liu EH, Shim J, Naruse K, Csete ME, Thouless MD, Takayama S. Fabrication of reconfigurable protein matrices by cracking. Nat Mater. 2005; 4(5): 403-6. [Medline] [CrossRef]

7. Katanosaka Y, Iwasaki K, Ujihara Y, Takatsu S, Nishitsuji K, Kanagawa M, Sudo A, Toda T, Katanosaka K, Mohri S, Naruse K. TRPV2 is critical for the maintenance of cardiac structure and function in mice. Nat Commun. 2014; 5: 3932. [Medline] [CrossRef]

8. Ito S, Kume H, Naruse K, Kondo M, Takeda N, Iwata S, Hasegawa Y, Sokabe M. A novel Ca2+ influx pathway activated by mechanical stretch in human airway smooth muscle cells. Am J Respir Cell Mol Biol. 2008; 38(4): 407-13. [Medline] [CrossRef]

9. Nagai Y, Yokoi H, Kaihara K, Naruse K. The mechanical stimulation of cells in 3D culture within a self-assembling peptide hydrogel. Biomaterials. 2012; 33(4): 1044-51. [Medline] [CrossRef]

10. Komatsu S, Nagai Y, Naruse K, Kimata Y. The neutral self-assembling peptide hydrogel SPG-178 as a topical hemostatic agent. PLoS One. 2014; 9(7): e102778. [Medline] [CrossRef]

11. Takayama S, Ostuni E, LeDuc P, Naruse K, Ingber DE, Whitesides GM. Subcellular positioning of small molecules. Nature. 2001; 411(6841): 1016. [Medline] [CrossRef]

12. Matsuura K, Hayashi N, Kuroda Y, Takiue C, Hirata R, Takenami M, Aoi Y, Yoshioka N, Habara T, Mukaida T, Naruse K. Improved development of mouse and human embryos using a tilting embryo culture system. Reprod Biomed Online. 2010; 20(3): 358-64. [Medline] [CrossRef]

13. Hara T, Matsuura K, Kodama T, Sato K, Kikkawa Y, Muneto T, Tanaka J, Naruse K. A tilting embryo culture system increases the number of high-grade human blastocysts with high implantation competence. Reprod Biomed Online. 2013; 26(3): 260-8. [Medline] [CrossRef] 